\title{
Commentary: Prevalence, Predictors, and Treatment of Imposter Syndrome: A Systematic Review
}

\author{
Dena M. Bravata',2*, Divya K. Madhusudhan'2, Michael Boroff², Kevin O. Cokley ${ }^{3}$ \\ 'Center for Primary Care and Outcomes Research, Stanford University School of Medicine, Stanford, CA \\ ${ }^{2}$ Crossover Health, San Clemente, CA \\ ${ }^{3}$ University of Texas at Austin, Austin, TX
}

\section{Article Info}

\section{Article Notes}

Received: June 30, 2020

Accepted: August 24, 2020

\section{${ }^{*}$ Correspondence:}

Dr. Dena M. Bravata, M.D., M.S.; Senior Affiliate, Center for Primary Care and Outcomes Research, Stanford University

School of Medicine; 1840 Lexington Av, San Mateo CA;

Telephone No: 415-706-5829; Email: dbravata@gmail.com.

(C) 2020 Bravata DM. This article is distributed under the terms of the Creative Commons Attribution 4.0 International License.

\section{Keywords:}

Imposter syndrome

Impostor syndrome

Behavioral Health

Occupational Health

\section{Introduction}

Imposter syndrome is a condition that describes high-achieving individuals who, despite their objective successes, fail to internalize their accomplishments and have persistent self-doubt and fear of being exposed as a fraud or imposter ${ }^{1}$. Individuals struggling with imposter syndrome do not attribute their performance to their actual competence, instead ascribe their successes to external factors such as luck or help from others while considering setbacks as evidence of their professional inadequacy ${ }^{2}$.

In December 2019, we published the first systematic review of the published literature on imposter syndrome ${ }^{1}$. In that study, we evaluated the 62 peer-reviewed studies of 14,161 individuals with imposter syndrome published between January 1966 and May $2018^{3-68}$. Initially described by psychologists Clance and Imes in 1978 among high-achieving professional women ${ }^{2}$, we sought to evaluate the evidence from the subsequent four decades of published literature on the prevalence of imposter syndrome in employed populations, characterize its relationship to workplace performance and burnout, describe common co-morbidities, and determine the most effective treatments for populations suffering from imposter symptoms.

The purpose of this commentary is to highlight the key findings of our previously published meta-analysis ${ }^{1}$ and discuss those results in light of the current COVID-19 pandemic and national discussion regarding racial equality.

\section{Prevalence of Imposter Syndrome}

The published literature on imposter syndrome is comprised exclusively of evaluations of cohorts to assess the prevalence of imposter syndrome and describe their psychiatric and psychological co-morbidities ${ }^{1}$. The prevalence of imposter syndrome varies widely from $9 \%$ to $82 \%$, largely depending on the recruitment strategy for the study (e.g., population-based evaluations, studies of students), screening tool used (e.g., Clance Imposter Phenomenon Scale ${ }^{69}$, Harvey Impostor Phenomenon Scale ${ }^{70}$ ) and cutoff used to assess symptoms ${ }^{1}$. The literature on the prevalence of imposter syndrome may be subject to publication bias (i.e., the tendency of journals to publish studies with positive findings rather than negative findings) since all of the peer-reviewed studies reported some participants endorsing imposter feelings ${ }^{1}$. 
Although much of the earliest literature focused on women, it is clear that imposter syndrome affects both men and women (although 16 articles found greater symptoms of imposter syndrome among women ${ }^{17,22,27,29-33,36,37,40,44,51,56,57,67}$, 17 articles found no gender effect). Additionally, imposter syndrome affects individuals across the age spectrum (two studies reported that increased age was associated with decreased imposter feelings ${ }^{12,64}$ while three studies found no age effect ${ }^{43,56,68}$ ).

\section{Imposter Syndrome Among Employees}

The meta-analysis found that people with imposter syndrome aggressively pursue achievement while not being able to accept recognition when success is achieved ${ }^{1}$. Thus, in the workplace, those affected with imposter syndrome may experience increased levels of stress, burnout, and decreased job performance and satisfaction over time ${ }^{1}$. Employees who persistently question their professional legitimacy may also be at higher risk for experiencing adverse psychological outcomes with implications for career retention and advancement.

When employees with imposter syndrome are faced with more responsibility and less supervision their symptoms of self-doubt and fears of being exposed as a fraud have been shown to increase ${ }^{1}$. Since the COVID-19 pandemic, healthcare professionals and employees of companies who have had to reduce their workforce may be experiencing both of these circumstances. Additionally, employees who remain at work with a reduced workforce due to the financial crisis resulting from the pandemic may face "survivor guilt" which has also been associated with imposter syndrome ${ }^{31}$.

Crawford et al. found a significant relationship between imposter syndrome and self-reported conflict managing work/life balance among affected employees ${ }^{20}$. However, they found that this relationship was minimized if employees perceived that they were given greater organizational support $^{20}$. Employees who are working from home for the first time may feel less supported by supervisors and managers. The situation may be complicated especially for those with caregiver responsibilities at home, assisting children with home-schooling, and facing new work/ life balance issues. Employers and managers may need education in the recognition of imposter syndrome and in the development of both structured (e.g., training, orientation) and unstructured learning and career development activities (e.g., mentoring, coaching, selfdirected learning) to help employees at this time ${ }^{1}$. Offering resources such as access to therapy and resilience trainings that focus on imposter syndrome could help identify and reduce the symptoms of imposter syndrome in employed populations. In addition, employers can mitigate the effects of imposter syndrome by creating healthier expectations and cultures where mistakes are not interpreted as failures and publicly acknowledging and celebrating employee accomplishments.

\section{The Treatment of Imposter Syndrome and its Co-Morbidities}

Imposter syndrome often co-exists with depression $^{35,41-43,51,56,63,71}$, anxiety $28,35,72,73$, low self-esteem ${ }^{52,56}$, somatic symptoms and social dysfunction ${ }^{35}$. Critically, there have been no trials of therapeutic interventions to treat individuals with imposter syndrome ${ }^{1}$. Given the absence of specific treatment recommendations for imposter syndrome and the prevalence of co-morbidities, we encourage clinicians to rigorously screen patients presenting with imposter syndrome for depression and anxiety and offer evidence-based therapies for these conditions. Additionally, since individuals experiencing imposter syndrome often perceive themselves to be the "only one" having these feelings, resulting in even greater isolation, referral to group therapy in which peers/coworkers discuss their feelings of doubt and failure might be particularly therapeutic. Clinicians and other highachieving professionals may be reluctant to participate in such groups unless they are carefully designed to normalize and destigmatize imposter feelings and provide a safe environment in which to share experiences openly. We encourage all clinicians (including mental health specialists) to pursue training on the common presenting symptoms, prevalence, and strategies for addressing imposter syndrome.

\section{Race / Ethnicity and Imposter Syndrome}

Eleven studies evaluated imposter syndrome among minority student populations $s^{6,7,4,15-17,23,45,46,48,58,67}$. These studies found that imposter syndrome is common among African-, Asian-, and Latino/a-American college students and that imposter feelings are significantly negatively associated with poor psychological well-being, depression, and anxiety. These studies identified several factors that may predispose minority students to increased psychological stress during their educational experiences including lack of adequate financial aid resulting in the need to work to support themselves financially, racial discrimination, and being the first in their families to pursue advanced education ${ }^{74,75}$. Given the current environment of financial uncertainty for all students and recent graduates, there may be an increase in the number of individuals suffering from imposter feelings.

Interestingly, one study found that imposter feelings were stronger predictors of impaired mental health than the stress of the individual's minority status ${ }^{75}$. This is particularly significant given that research on ethnic minority populations tends to focus on their minority status and presumed experiences of discrimination, rather 
than the individual differences within a minority group such as the presence or absence of imposter feelings ${ }^{75}$. In the literature, attempts to standardize imposter syndrome assessment tools typically include only small numbers of ethnic minorities, which raises questions of whether current imposter syndrome screening tools are valid for ethnic minority populations.

There is some evidence to suggest that for ethnic minority populations there is a racial component of impostor feelings ${ }^{76,77}$. For example, a recent qualitative study with Black graduate students found five themes related to impostor feelings: awareness of low racial representation, questioning intelligence, expectations, psychosocial costs, and explaining success externally ${ }^{76}$. It may be prudent to consider that the clinical definition of impostor syndrome be culturally adjusted to properly assess minority students in order to help them navigate feelings of otherness and racial isolation and the "need to prove themselves" on the basis of their race $^{76}$.

\section{Imposter Syndrome as a Disorder}

Half of the 62 peer-reviewed publications on imposter syndrome were published in the last seven years underscoring the recent recognition of imposter syndrome as an important clinical phenomenon. Despite this, however, imposter syndrome is not a recognized psychiatric disorder; it is neither featured in the American Psychiatric Association's Diagnostic and Statistical Manual $5^{\text {th }}$ Edition (DSM-5) ${ }^{9}$ nor in the International Classification of Diseases, Tenth Revision (ICD-10) ${ }^{10}$. Imposter syndrome should be considered for rapid inclusion in the next edition of the DSM so that patients with these symptoms can be identified and treated by behavioral health providers. This would also facilitate research on therapeutic interventions for this population, evaluate the effect of the pandemic on affected individuals, and assist in further assessments of the impact of racial and ethnic issues on mental health.

\section{Conclusion}

This analysis suggests that imposter symptoms are prevalent among men and women, members of multiple ethnic groups, and are significantly associated with worsened experiences in professional settings ${ }^{1}$. Given that imposter syndrome largely affects how individuals perceive their accomplishments in the workplace, we recommend that clinicians screen patients presenting with employment-related complaints (e.g., difficulty with managers or co-workers, work-life balance issues, workplace performance anxiety) for imposter syndrome. The literature lacks consensus about evidence-based treatments for patients with imposter syndrome. Mental health professionals, educators, and employers must be educated about imposter syndrome to take steps to mitigate the psychological impact of this condition. We recommend a prospective evaluation of the use of individual and group cognitive behavioral therapy focused on addressing imposter feelings on clinical and workplace outcomes for employed populations across a range of professions.

\section{Acknowledgements}

Funding Source: Drs. Bravata and Boroff and Ms. Madhusudhan were either employees of or consultants to Crossover Health, the funder of this study. Dr. Cokley received no financial support for his participation in this study.

\section{References}

1. Bravata DM, Watts SA, Keefer AL, et al. Prevalence, Predictors, and Treatment of Impostor Syndrome: a Systematic Review. J Gen Intern Med. 2020; 35(4): 1252-1275.

2. Clance $\mathrm{P}$, Imes $\mathrm{S}$. The imposter phenomenon in high achieving women: Dynamics and therapeutic intervention. Psychotherapy: Theory, Research \& Practice. 1978; 15(3): 241-247.

3. Ares TL. Role Transition After Clinical Nurse Specialist Education Clinical nurse specialist CNS. 2018; 32(2): 71-80.

4. Austin CC, Clark EM, Ross MJ, et al. Impostorism as a mediator between survivor guilt and depression in a sample of African American college students. College Student Journal. 2009; 43(4, PtA): 1094-1109.

5. Bechtoldt MN. Wanted: Self-doubting employees-Managers scoring positively on impostorism favor insecure employees in task delegation. Pers Individ Dif. 2015; 86: 482-486.

6. Bernard DL, Lige QM, Willis HA, et al. Impostor phenomenon and mental health: The influence of racial discrimination and gender. J Couns Psychol. 2017; 64(2): 155-166.

7. Bernard DL, Hoggard LS, Neblett EW. Racial discrimination, racial identity, and impostor phenomenon: A profile approach. Cultural Diversity and Ethnic Minority Psychology. 2018; 24(1): 51-61.

8. Brauer K, Proyer RT. Are impostors playful? Testing the association of adult playfulness with the Impostor Phenomenon. Pers Individ Dif. 2017; 116: 57-62.

9. Byrnes KD, Lester D. The imposter phenomenon in teachers and accountants. Psychol Rep. 1995; 77(1): 350-350.

10. Caselman TD, Self PA, Self AL. Adolescent attributes contributing to the imposter phenomenon. J Adolesc. 2006; 29(3): 395-405.

11. Castro DM, Jones RA, Mirsalimi H. Parentification and the impostor phenomenon: An empirical investigation. Am J Fam Ther. 2004; 32(3): 205-216.

12. Chae JH, Piedmont RL, Estadt BK, et al. Personological evaluation of Clance's Impostor Phenomenon Scale in a Korean sample. J Pers Assess. 1995; 65(3): 468-485.

13. Chayer $\mathrm{MH}$, Bouffard T. Relations between impostor feelings and upward and downward identification and contrast among 10- to 12-year-old students. European Journal of Psychology of Education. 2010; 25(1): 125-140.

14. Christensen M, Aubeeluck A, Fergusson D, et al. Do student nurses experience Imposter Phenomenon? An international comparison of Final Year Undergraduate Nursing Students readiness for registration. J Adv Nurs. 2016; 72(11): 2784-2793.

15. Cokley K, McClain S, Enciso A, et al. An examination of the impact of minority status stress and impostor feelings on the mental health of diverse ethnic minority college students. Journal of Multicultural Counseling and Development. 2013; 41(2): 82-95. 
16. Cokley K, Smith L, Bernard D, et al. Impostor feelings as a moderator and mediator of the relationship between perceived discrimination and mental health among racial/ethnic minority college students. Couns Psychol. 2017; 64(2): 141-154.

17. Cokley K, Awad G, Smith L, et al. The roles of gender stigma consciousness, impostor phenomenon and academic self-concept in the academic outcomes of women and men. Sex Roles. 2015; 73(910): 414-426.

18. Cowman SE, Ferrari JR. Am I for real? Predicting impostor tendencies from self-handicapping and affective components. Social Behavior and Personality: An international journal. 2002; 30(2): 119-126.

19. Cozzarelli C, Major B. Exploring the validity of the impostor phenomenon. J Soc Clin Psychol. 1990; 9(4): 401-417.

20. Crawford WS, Shanine KK, Whitman MV, et al. Examining the impostor phenomenon and work-family conflict. Journal of Managerial Psychology. 2016; 31(2): 375-390.

21. Cromwell B, Brown NW, Sanchez-Huceles J, et al. The Impostor Phenomenon and personality characteristics of high school honor students. Journal of Social Behavior \& Personality. 1990; 5(6): 563-573.

22. Cusack CE, Hughes JL, Nuhu N. Connecting gender and mental health to imposter phenomenon feelings. Psi Chi Journal of Psychological Research. 2013; 18(2): 74-81.

23. Ewing KM, Richardson TQ James-Myers L, et al. The relationship between racial identity attitudes, worldview, and African American graduate students' experience of the imposter phenomenon. J Black Psychol. 1996; 22(1): 53-66.

24. Ferrari JR. Impostor tendencies and academic dishonesty: Do they cheat their way to success? Soc Behav Pers. 2005; 33(1): 11-18.

25. Ferrari JR, Thompson T. Impostor fears: Links with self-presentational concerns and self-handicapping behaviours. Pers Individ Dif. 2006 40(2): 341-352.

26. Fried-Buchalter S. Fear of success, fear of failure, and the imposter phenomenon among male and female marketing managers. Sex Roles. 1997; 37(11-12): 847-859.

27. Ghorbanshirodi S. The relationship between self-esteem and emotional intelligence with imposter syndrome among medical students of Guilan and Heratsi Universities. Journal of Basic and Applied Scientific Research. 2012; 2(2): 1793-1802.

28. Gibson-Beverly G, Schwartz JP. Attachment, entitlement, and the impostor phenomenon in female graduate students. Journal of College Counseling. 2008; 11(2): 119-132.

29. Hayes KM, Davis SF. Interpersonal flexibility, Type A individuals, and the impostor phenomenon. Bulletin of the Psychonomic Society. 1993; 31(4): 323-325.

30. Henning K, Ey S, Shaw D. Perfectionism, the impostor phenomenon and psychological adjustment in medical, dental, nursing and pharmacy students. Med Educ. 1998; 32(5): 456-464.

31. Hutchins HM, Rainbolt $\mathrm{H}$. What triggers imposter phenomenon among academic faculty? A critical incident study exploring antecedents, coping, and development opportunities. Human Resource Development International. 2017; 20(3): 194-214.

32. Hutchins HM, Penney LM, Sublett LW. What imposters risk at work Exploring imposter phenomenon, stress coping, and job outcomes. Human Resource Development Quarterly. 2017.

33. Jostl G, Bergsmann E, Luftenegger M, et al. When will they blow my cover? The impostor phenomenon among Austrian doctoral students. Z Psychol. 2012; 220(2): 109-120.

34. Kamarzarrin H, Khaledian M, Shooshtari M, et al. A study of the relationship between self-esteem and the imposter phenomenon in the physicians of Rasht city (Iran). Eur J Exp Biol. 2013; 3(2): 363-366.
35. Kananifar N, Seghatoleslam T, Atashpour SH, et al. The relationships between imposter phenomenon and mental health in Isfahan universities students. International Medical Journal. 2015; 22(3): 144-146.

36. King JE, Cooley EL. Achievement orientation and the impostor phenomenon among college students. Contemp Educ Psychol. 1995 20(3): 304-312.

37. Kumar S, Jagacinski CM. Imposters have goals too: The imposter phenomenon and its relationship to achievement goal theory. Pers Individ Dif. 2006; 40(1): 147-157.

38. LaDonna KA, Ginsburg S, Watling C. "Rising to the Level of Your Incompetence": What Physicians' Self-Assessment of Their Performance Reveals About the Imposter Syndrome in Medicine. Academic Medicine: Journal of The Association Of American Medical Colleges. 2018; 93(5): 763-768.

39. Leary MR, Patton KM, Orlando AE, et al. The impostor phenomenon: Self-perceptions, reflected appraisals, and interpersonal strategies. J Pers. 2000; 68(4): 725-756.

40. Legassie J, Zibrowski EM, Goldszmidt MA. Measuring resident wellbeing: Impostorism and burnout syndrome in residency. J Gen Intern Med. 2008; 23(7): 1090-1094.

41. Leonhardt M, Bechtoldt MN, Rohrmann S. All impostors aren't alikeDifferentiating the impostor phenomenon. Front Psychol. 2017; 8.

42. Rohrmann S, Bechtoldt MN, Leonhardt M. Validation of the impostor phenomenon among managers. Front Psychol. 2016; 7.

43. Lester D, Moderski T. The imposter phenomenon in adolescents. Psychol Rep. 1995; 76(2): 466.

44. Li S, Hughes JL, Thu SM. The links between parenting styles and imposter phenomenon. Psi Chi Journal of Psychological Research. 2014; 19(2): 50-57.

45. Lige QM, Peteet BJ, Brown CM. Racial identity, self-esteem, and the impostor phenomenon among African American college students. J Black Psychol. 2017; 43(4): 345-357.

46. Peteet BJ, Brown CM, Lige QM, et al. Impostorism is associated with greater psychological distress and lower self-esteem for African American students. Current Psychology: A Journal for Diverse Perspectives on Diverse Psychological Issues. 2015; 34(1): 154-163.

47. Matthews G, Clance PR. Treatment of the impostor phenomenon in psychotherapy clients. Psychotherapy in Private Practice. 1985; 3(1): 71-81.

48. McClain S, Beasley ST, Jones B, et al. An examination of the impact of racial and ethnic identity, impostor feelings, and minority status stress on the mental health of Black college students. Journal of Multicultural Counseling and Development. 2016; 44(2): 101-117.

49. McElwee ROB, Yurak TJ. Feeling versus acting like an impostor: Real feelings of fraudulence or self-presentation? Individual Differences Research. 2007; 5(3): 201-220.

50. McElwee ROB, Yurak T]. The phenomenology of the impostor phenomenon. Individual Differences Research. 2010; 8(3): 184-197.

51. McGregor LN, Gee DE, Posey KE. I feel like a fraud and it depresses me: The relation between the imposter phenomenon and depression. Soc Behav Pers. 2008; 36(1): 43-48.

52. Neureiter M, Traut-Mattausch E. An inner barrier to career development: Preconditions of the impostor phenomenon and consequences for career development. Front Psychol. 2016; 7.

53. Neureiter M, Traut-Mattausch E. Inspecting the Dangers of Feeling like a Fake: An Empirical Investigation of the Impostor Phenomenon in the World of Work. Front Psychol. 2016; 7: 1445-1445.

54. Neureiter M, Traut-Mattausch E. Two sides of the career resources 
coin: Career adaptability resources and the impostor phenomenon. J Vocat Behav. 2017; 98: 56-69.

55. Okoth A, Moderski T, Lester D. Impostor feelings in disturbed adolescents. Psychol Rep. 1994; 75(3, Pt 2): 1538-1538.

56. Oriel K, Plane MB, Mundt M. Family Medicine Residents and the Impostor Phenomenon. Fam Med. 2004; 36(4): 248-252.

57. Patzak A, Kollmayer M, Schober B. Buffering impostor feelings with kindness: The mediating role of self-compassion between gender-role orientation and the impostor phenomenon. Front Psychol. 2017; 8.

58. Peteet BJ, Montgomery L, Weekes JC. Predictors of imposter phenomenon among talented ethnic minority undergraduate students. Journal of Negro Education. 2015; 84(2): 175-186.

59. Robinson SL, Goodpaster SK. The effects of parental alcoholism on perception of control and imposter phenomenon. Current Psychology: A Journal for Diverse Perspectives on Diverse Psychological Issues. 1991; 10(1-2): 113-119.

60. Schubert N, Bowker A. Examining the impostor phenomenon in relation to self-esteem level and self-esteem instability. Current Psychology: A Journal for Diverse Perspectives on Diverse Psychological Issues. 2017.

61. Selby CLB, Mahoney MJ. Psychological and physiological correlates of self-complexity and authenticity. Constructivism in the Human Sciences. 2002; 7(1-2): 39-52.

62. September AN, McCarrey M, Baranowsky A, et al. The relation between well-being, impostor feelings, and gender role orientation among Canadian university students. The Journal of social psychology. 2001; 141(2): 218-232.

63. Sonnak C, Towell T. The impostor phenomenon in British university students: Relationships between self-esteem, mental health, parental rearing style and socioeconomic status. Pers Individ Dif. 2001; 31(6): 863-874.

64. Thompson T, Davis H, Davidson J. Attributional and affective responses of impostors to academic success and failure outcomes. Pers Individ Dif. 1998; 25(2): 381-396.

65. Thompson T, Foreman P, Martin F. Impostor fears and perfectionist concern over mistakes. Pers Individ Dif. 2000; 29(4): 629-647.

66. Vergauwe J, Wille B, Feys M, et al. Fear of being exposed: The trait- relatedness of the impostor phenomenon and its relevance in the work context. J Bus Psychol. 2015; 30(3): 565-581.

67. Villwock JA, Sobin LB, Koester LA, et al. Impostor syndrome and burnout among American medical students: a pilot study. International journal of medical education. 2016; 7: 364-369.

68. Want J, Kleitman S. Imposter phenomenon and self-handicapping: Links with parenting styles and self-confidence. Pers Individ Dif. 2006; 40(5): 961-971.

69. Clance PR, O'Toole MA. The Imposter Phenomenon: An internal barrier to empowerment and achievement. Women Ther. 1987; 6(3): 51-64.

70. Harvey JC. The Impostor Phenomenon and Achievements: A Failure to Internalize Success. In: International DA, ed. PA: Templte University; 1981: 4969-4970B.

71. Chrisman SM, Pieper WA, Clance PR, et al. Validation of the Clance Imposter Phenomenon Scale. J Pers Assess. 1995; 65(3): 456-467.

72. Bernard NS, Dollinger SJ, Ramaniah NV. Applying the big five personality factors to the impostor phenomenon. J Pers Assess. 2002; 78(2): 221-233.

73. Ross SR, Stewart J, Mugge M, et al. The imposter phenomenon, achievement dispositions, and the Five Factor Model. Pers Individ Dif. 2001; 31(8): 1347-1355.

74. Ewing K, Richardson T, James-Myers L, et al. The relationship between racial identity attitudes, worldview, and African American graduate students' experience of the imposter phenomenon. J Black Psychol. 1996; 22(1): 53-66.

75. Cokley K, McClain S, Enciso A, et al. An examination of the impact of minority status stress and impostor feelings on the mental health of diverse ethnic minority college students. J Multicult Couns Dev. 2013; 41(2): 82-95.

76. Stone S, Saucer C, Bailey M, et al. Learning While Black: A Culturally Informed Model of the Impostor Phenomenon for Black Graduate Students. J Black Psychol. 2018; 44(6): 491-531.

77. Bernard DL, Jones SC, Volpe VV. Impostor phenomenon and psychological well-being: The moderating roles of John Henryism and school racial composition among Black college students. J Black psychol. 2020. 